\title{
O Zé Povinho nas trincheiras: epopeia e anedota no memorialismo da Grande Guerra
}

Paulo Alexandre Cardoso Pereira"

\section{Resumo}

No presente artigo, partindo de uma leitura panorâmica dos textos de alguns memorialistas portugueses da Grande Guerra (Jaime Cortesão, Augusto Casimiro, Pina de Morais, Albino Forjaz de Sampaio e André Brun, entre outros), são examinadas algumas estratégias de reencenação narrativa da memória pós-traumática, com destaque para o efeito de dissonância estilística que neles se detecta entre um registo épico-celebratório e uma miniloquência de tom elegíaco ou burlesco. Essa oscilação retórica é, em seguida, relacionada com uma essencial mutação da política e da poética da memória que nesses textos se torna inteligível e em função da qual o lugar do herói épico do passado parece ter sido ocupado pela figura anónima do Soldado Desconhecido.

Palavras-chave: Memorialismo de guerra. Literatura de testemunho. Humor. Soldado Desconhecido.
Human kind / Cannot bear very
much reality.

T. S. Eliot, Four Quartets

Introdução

No conhecido ensaio intitulado $E x$ periência e pobreza (1933), Walter Benjamin examina os sintomas do que considera a emergência de uma "nova barbárie" (2012, p. 86). Descrevendo-a como "uma forma de pobreza totalmente nova" (2012, p. 86), expressa no declínio contemporâneo da experiência comunicável, Benjamin sustenta que as origens desse silêncio em face de um conhecimento que não pode partilhar-se devem ser procuradas na experiência apocalíptica inédita da Primeira Guerra:

\footnotetext{
Doutor em Literatura pela Universidade de Aveiro. Exerce funções como professor auxiliar no Departamento de Línguas e Culturas da Universidade de Aveiro, onde tem lecionado várias disciplinas de licenciatura e mestrado na área da Literatura Portuguesa e desenvolvido atividades de investigação no domínio dos Estudos Literários. É investigador no Centro de Línguas, Literaturas e Culturas, da Universidade de Aveiro. E-mail: ppereira@ua.pt
}

Data de submissão: fev. 2018 - Data de aceite: jun. 2018 http://dx.doi.org/10.5335/rdes.v14i2.7897 
Uma coisa é clara: a cotação da experiência baixou, e isso aconteceu com uma geração que fez, em 1914-1918, uma das experiências mais monstruosas da história universal. Talvez isso não seja tão estranho como parece. Não se tinha, naquela época, a experiência de que os homens voltavam mudos do campo de batalha? Não voltavam mais ricos, mas mais pobres de experiências partilháveis. Aquilo que, dez anos mais tarde, fomos encontrar na grande vaga dos livros de guerra, era tudo menos experiência contada e ouvida. [...] Uma geração que ainda foi à escola nos carros puxados a cavalos, viu-se de repente num descampado, numa paisagem em que nada se manteve inalterado a não ser as nuvens, e no meio dela, num campo de forças de correntes e explosões destruidoras, o corpo humano minúsculo e frágil (2012, p. 86).

Com ânimo conclamador e esperança redentorista, tinha Almada, em 1917, no Ultimatum futurista às gerações portuguesas do século $X X$, proclamado, em sentido inverso, que "A guerra é a grande experiência" (NEGREIROS, 1984, p. 38). Esses diagnósticos aparentemente discordes - descontando, bem entendido, os contextos substancialmente diversos em que foram formulados - tornam legível a aporia que permeia a literatura de testemunho: se o "dever de memória" (RICEUUR, 2000, p. 37) impõe à testemunha a indeclinável tarefa ética de narrar o inenarrável, essa urgência de recomposição mnésica confronta-a tam- bém com a impossível exemplaridade da sua experiência e o colapso da linguagem perante um excesso inabarcável de real. É dessa "incomensurabilidade entre as palavras e a experiência da morte" (SELIGMANN-SILVA, 2010, p. 9) que transcorre o impasse de representação que insistentemente assombra as escritas de guerra de que aqui nos iremos ocupar.

\section{Contar a catástrofe: os impasses da mimese}

É certo que, no copioso corpus documental, de cariz histórico-literário, produzido a propósito da participação portuguesa na Grande Guerra, avultam, com sintomática proeminência, os géneros de orientação autobiográfica-memorialística - diários, memórias, crónicas - agregados em torno de uma "matriz dominante de depoimento vivencial guerrista" (LEAL, 2000, p. 442). Mas é também indesmentível que essa "estética da experiência direta" (WINTER, 1995 , p. 2) ${ }^{1}$ ou o "imperativo mimético" (BOAK, 2012, p. 219) que lhe subjaz impôs, desde logo, a preterição da dicção elevada, apologética e ufanista que tonalizava grande parte da literatura de guerra e que Wilfred Owen condensou lapidarmente no poema "The Old Lie: Dulce et decorum est pro patria mori" ${ }^{3}$. A desconcertante descoberta de que a guerra tinha esvaziado a maioria das antigas palavras do seu significado e a consciência da sua abstrata inoperância perante a inverosímil magnitude da catástrofe ${ }^{4}$ 
parecem ir de par com uma retração da linguagem ou, pelo menos, com uma irredimível suspeição relativamente aos seus poderes reparadores. Enjeitando a tese da inefabilidade do horror, Paul Fussell adianta ainda uma outra justificação para o silêncio dos soldados regressados das trincheiras: "The real reason is that soldiers have discovered that no one is very interested in the bad news they have to report. What listener wants to be torn and shaken when he doesn't have to be? We have made unspeakable mean indescribable: it really means nasty" (FUSSELL, 2000, p. 170).

Argumenta-se, na leitura panorâmica que aqui se propõe de alguns memorialistas portugueses da Grande Guerra Jaime Cortesão, Augusto Casimiro, Pina de Morais, Albino Forjaz de Sampaio e André Brun -, que a indecidibilidade que afeta a reencenação autobiográfica da memória pós-traumática - vacilante entre querer contar e estar ciente da irredutibilidade desse excesso de real a qualquer narrativa - permite compreender o duplo gesto retórico que se torna ostensivo nesses textos, alternado sempre entre a gravitas marcial do hino e o burlesco light-hearted da comédia castrense, a ênfase celebratória e a miniloquência, o pathos e o bathos - em síntese, entre a "epopeia maldita", para retomar o título-programa de António de Cértima $^{5}$, e a anedota que, lateralizando ou diferindo o inominável da guerra, permite uma revisitação oblíqua do retorno do recalcado pós-traumático ${ }^{6}$. Consig- nando a inesperada convivialidade entre o derrisório e o catastrófico, este realismo traumático ${ }^{7}$ permite compreender que, como se refere em Ao parapeito, de Pina de Morais, "Os que fazem a guerra é raro falarem dela. Lá se conta uma história ou outra" (MORAIS, 1919, p. 101). Este canto épico descentrado - que ao sublime do pathos não raras vezes prefere a trivialidade do bathos - surge, assim, vertido em escritos transicionais, de sintaxe episódica, que, com modéstia evasiva, os autores descrevem como impressões, notas, retalhos ${ }^{8}$ ou, como prefere André Brun, migalhas, justificando, nos seguintes termos, o seu programa de humilis narratio:

Não é este um livro ad probandum. Esse virá a seu tempo. Devo-o aos meus soldados e a mim próprio. O presente volume $a d$ narrandum é apenas uma documentação pitoresca, um relato do que eu vi com os que a terra há-de comer, olhos da minha cara e mortos da minha pátria.

Talvez porque as tendências naturais do meu espírito me não concedam facilmente aquela faculdade que um personagem de Eça se atribuirá de «saborear o grandioso»; talvez porque as circunstâncias e os homens mais do que elas não habilitaram o Corpo Expedicionário Português a escrever, por enquanto, aquele canto de epopeia que os patriotas esperavam e os retóricos prometiam, este livro é um livro de crónicas, direi mesmo um livro de anedotas (BRUN, 2014, p. 20).

Em Nas Trincheiras da Flandres, de Augusto Casimiro, esse gesto prefacial de derrogação épica distancia-se explicitamente da retórica inflacionada dos "palavrosos escrivães", deposta em benefício de uma ética-poética do silêncio: 
Ninguém procure nele [no livro] visões teatrais de epopeia, Não as vi na guerra. Só as vê quem nunca fez a guerra, esta guerra, senhores!

Eu não podia vê-las... E não quero merecer-me, e aos meus camaradas de França, a indignação com que na trincheira lemos os lugares comuns dos cronistas ausentes, palavrosos escrivães que não sabem o que seja a austera severidade dos que cumprem o seu dever na lama, no sangue, em luta consigo e com todas as forças tumultuosas e miseráveis... Perto da Morte - essa que nos ensinou graves silêncios... (CASIMIRO, 1917, p. 7).

Num revelador diálogo com Hernâni Cidade, que Augusto Casimiro encontrara na frente da Flandres, reemerge essa nostalgia da epopeia numa wasteland desabitada de deuses e de heróis:

Fomos ao parapeito. Hernâni Cidade, querido irmão, aparecera no momento. Os três falámos da guerra.

- “Onde a epopeia!" -

- "Meu pobre Homero, que pensarias disto?" - (1917, p. 57)

Confrontados com a desfuncionalização retórica da elocução épica, tornada absurda num mundo de caos apocalíptico, extinto o otimismo antropológico e desmantelada a axiologia sólida que escorava o canto congregador de sentido mítico-utópico, os memorialistas da guerra viram-se, no fundo, impelidos a interrogar as "possibilités de convergence entre l'aspiration à dire la totalité, sur laquelle se fonde traditionellement ce chant fédérateur qu'est l'épopée, et les fondements d'une esthétique de la ruine et du fragmentaire, si caractéristique de la modernité" (NEIVA, 2009, p. xi).
Essa inflexão dos códigos da epopeia não redundará, ressalve-se desde já, no cancelamento das leituras patriótico-triunfalistas desenvolvidas em torno da participação portuguesa no conflito, exemplarmente documentadas nas colaborações coligidas no número especial que, em 1916, A Águia dedica a Portugal e a Guerra. No prefácio às suas Memórias da Grande Guerra, Jaime Cortesão reclama a dignidade epopeica da matéria disponibilizada pela ação dos combatentes portugueses nas trincheiras, dissociando-se da linha do pitoresco antiépico que prevalecia nos "relatos frustes":

Há quem pretenda, - eu sei, - que esta, a nossa guerra, não dá um canto de epopeia. Que é mero assunto para relatos frustes, coisas de somenos, frioleiras. Felizmente os que assim falam não definem a nossa guerra mas o seu temperamento, marcado pela faculdade estreita de ver o riso e a espuma das coisas.

Nem por isso a nossa guerra, como as outras, deixa de se repassar de sofrimento e de epopeia. Para isso bastava a batalha do Lys e a arrancada épica daqueles homens, que, vencendo a inércia e a descrença dos grandes chefes, conseguem, através de tudo, marchar para a frente, onde se ganhava a vitória (CORTESÃO, 1969, p. 16-17).

Como sublinha Ernesto Castro Leal, "o guerrismo espelhado nos memorialismos republicanos de Jaime Cortesão, Augusto Casimiro, João Pina de Morais ou Carlos Selvagem transportava uma visão profética redentora, ancorada numa dupla justificação de sentido patriótico: a justificação política de aliados naturais do bloco demoliberal anglo-francês contra o expansionismo cesarista alemão; 
a justificação ética de uma proposta de revigoramento moral das energias nacionais que o soldado encarnava" (LEAL, 2000, p. 445). Apropriando-se do tropismo profético-messiânico, a partir do qual se justifica a excecionalidade do génio lusíada, bem como das declinações neorromânticas lusitanistas do Volksgeist, decantadas numa mística da grei, alguns destes memorialistas republicanos devolvem uma hiperidentidade eufórica amparada pela crença teleológica num desígnio histórico. Ciente do reconhecimento póstero da missão desempenhada ao serviço da pátria, Pina de Morais não tem dúvidas sobre a sua entronização no panteão dos santos e dos heróis: "Cumprimos o nosso dever, e as orações de Portugal inteiro, de centenares de gerações, pelos séculos alêm - virão em romagem para nos levarem ao campo sereno onde vivem os santos e os heróis" (1919, p. 896). Dinamizando uma poderosa mitologia da pátria e uma hermenêutica providencialista da sua história ${ }^{9}$, referenda-se uma metanarrativa imaginária legitimante, em função da qual os seus acontecimentos fundacionais são lidos em clave profético-alegórica e se faz entroncar a glória pessoal e coletiva "na cadeia biológica dos heróis do passado longínquo, constituindo deste modo uma meta-história para a qual se apela" (LEAL, 1992, p. 519).

Resgatando a imagem do Portugal descobridor, imperial e historicamente predestinado, um constante procedimento iterativo e analógico fará acercar a aetas aurea da expansão quinhentista da epopeia sangrenta da Flandres ${ }^{10}$. Para André Brun, a intervenção portuguesa no conflito reedita a «entrada de Portugal na Guerra Santa» (2014, p. 221) e um raid infernal dos boches sobre as linhas portuguesas, ocorrido na madrugada de 14 de Agosto, traz à memória do cronista 0 «aniversário de uma outra madrugada gloriosa: a de Aljubarrota» (2014, p. 212). Na buliçosa partida dos expedicionários de Alcântara-Mar, julga Jaime Cortesão entreouvir "os evoés da maruja que partia à Descoberta" (1969, p. 43) e o soldado português, certifica o narrador, "é ainda o mesmo de Aljubarrota e do Mar" (1969, p. 253). O desaire de La Lys é, no desalentado diagnóstico de um oficial, descrito como "o Alcácer-Quibir do C.E.P [Corpo Expedicionário Português]" (1969, p. 254). No pathos da partida dos contingentes portugueses para França, que Pina de Morais retrata em Ao parapeito, é premeditado o aceno intertextual à camoniana Praia das Lágrimas: "Fez-se quási o silêncio, e nos olhos chorosos das mulheres passou o orgulho antigo das mães e das mulheres dos heróis" (1919, p. 10). Por fim, remata o mesmo autor: "Sois bem - o lusitano! Sois bem o que combateu em Ormuz e nos Atoleiros, que partiu nas caravelas, que morreu em Alcácer-Quibir" (1919, p. 145) 


\section{Uma epopeia de "heróis de trazer por casa"}

É, no fim de contas, uma epopeia sem heróis - ou de "heróis de trazer por casa", como os descreve André Brun (2014, p. 157) - aquela que, no desamparo sem história do combatente anónimo, flagrantemente documentam estes cronistas da guerra ${ }^{11}$. O autor de A Malta das Trincheiras examina os motivos dessa deserção do heroico:

A guerra de trincheira não fornece aquele tipo de heróis que os paisanos de cinquenta anos para cima e as mulheres de dezoito anos para baixo esperavam, naquela figura de gravura ou oelografia atirando-se com uma espada na mão e um dito histórico na boca para o meio da baralha e para o seio da História.

Como se poderá ser herói segundo esse figurino nesta guerra em que todos andamos entalados entre traveses e pára-costas, com mil cuidados para que o inimigo nos não veja, e nunca conseguindo vê-lo, senão por acaso? [...]

O herói das trincheiras é um herói obscuro porque trabalha na escuridão [...]. Mas porque a sua heroicidade não tem espectáculo, nem por isso ela é menor, e ninguém a poderá entender tão bem como nós que vivemos dentro dela e a praticamos todos em dose maior ou menor. [...]

É uma heroicidade perpétua, obrigatória, profissional. Somos uns heróis de trazer por casa (BRUN, 2014, p. 157-159).

Cedo se torna incontestável que "nesta guerra com milhões de mortos, não haveria lugar ao culto do heroísmo individual (ao culto da personalidade), daí a poderosa liturgia cívica europeia colectiva ao Soldado Desconhecido, que a 'Pátria' coroará nos vários monumentos aos mortos da Grande Guerra" (LEAL, 2000, p. 566). Essa monumentalização da memória coletiva, alicerçada na celebração de uma gesta protagonizada por um herói sem rosto - ou melhor, com o rosto de todos os homens - explica os contornos arquetípicos, mesmo alegóricos, do soldado português. São manifestas as coincidências entre o retrato tipificado deste magala rude e rústico - "lapuz das Beiras e do Alentejo", como o descreve Carlos Selvagem (apud Leal, 2000, po. 448) - e a iconografia republicana do Zé Povinho. Como ele, representará, nos relatos de guerra, o emblema caricatural do homo lusitanus, face atávica e rasteira do psiquismo nacional. Se, como demonstrou João Medina, o espírito crítico-regenerador da Geração de 1970 tinha explorado, em regime imaginário de alternância complementar, os dois "polos da estereotipia nacional” (MEDINA, 1986, p. 11), respetivamente figurados no Zé Povinho e em Camões, no Labrego e no Bardo, é ainda a remanescência desse "dasein colectivo" (1986, p. 13) bipolar, balanceado entre o pícaro e o épico ${ }^{12}$, que parece intuir-se na conformação da imagem ambivalente do expedicionário português. $\mathrm{O}$ debate conjetural entre D. Quixote e Sancho Pança, atores imaginários da psicomaquia que se desenrola no teatro da consciência do capitão Augusto Casimiro, nos momentos que precedem o combate, reproduzido em Nas Trincheiras da Flandres, ilustra exemplarmente o idiossincrático heroísmo à portuguesa, cindido entre diligência épica e abulia pícara: 
E escuto, em mim:

- Vamos, depressa!... Os meus rapazes sofrem sob os morteiros... É provável que haja feridos, mortos, a esta hora... Apressa-te!... Êsse cordão da máscara, o capacete, vamos!...

- Sancho (manhoso, com grandes movimentos inquietos): - Lá vai o meu senhor e ano fazer mais uma das suas. Pois não me dirá vossa mercê a que vem essa mania? O dever de vossa mercê é deixar-se ficar por aqui, pois aqui é precisa a sua presença... Praza a Deus que essa mania não renda má morte, senhor meu amo...

- Dom Quixote (pondo o elmo do Mambrino usado pelo exército inglês...): - Como te enganas! Hás-de saber, Sancho, que é brio dos cavaleiros andantes procurar sempre sítio onde mostrem suas manhas e ilustrem sua gerarquia... Tanto mais agora, meu escudeiro, quando, na primeira linha, os meus rapazes sofrem o embate de gigantes ferozes contra quem não há coragem possível... Eu quero ser com êles, Sancho amigo, correr um risco igual ao deles, para que me vejam, para que em mim confiem... Assim, prepararemos, Sancho, as forças de alma necessárias para esta guerra dos demónios - que o senhor me perdõe...

- Sancho (atando a greva com uma lentidão voluntária): - Pois sim, pois sim, senhor D. Quixote... Mas ou eu me engano muito ou vossa mercê é o primeiro a dar-me razão pela pouca pressa que mostra em sair deste abrigo... E bem haja por isso... Que não nasceu tam apurado cavaleiro para ser assim arrasado estúpidamente por um morteiro médio... Pois diga-me vossa mercê, aqui, que só aquele ratinho nos ouve... Não está o meu amo neste sítio para dar as suas ordens e resolver à sua maneira o que cada um tem a fazer?... Por isso é muito bem feito dizer-se o que se diz...

- Cala-te, vilão! Que importa a murmuração dos vilões como tu? Vamos, acaba de apertar essa greva e toma a tua espingarda. Segue-me se quiseres...

- Que remédio tenho eu, meu amo!... (1917, p. 107-109).
A arquipersonagem do expedicionário português recebe nessas memórias de guerra nomes ou alcunhas que não deixam dúvidas sobre a sua estirpe pícara: ele é o Joaquim, em Albino Forjaz de Sampaio, o Esgalhado, em Jaime Cortesão, o José Maria Folgadinho, Lãzudo da Grande Guerra, em André Brun, o João Ninguém, no relato humorístico do $\mathrm{Ca}$ pitão Menezes Ferreira ${ }^{13}$. A etopeia que dele se traça é quase invariante: é "forte, parecendo um fraca figura, desempenado e resistente, parecendo débil", "tem como nenhum outro a pele dura, a alma terna, o riso pronto, a resposta fácil, a piada a tempo" (SAMPAIO, 1918, p. 194), é "chauvinista e repontão" (CORTESÃO, 1969 , p. 138), "herói de uma raça de femeeiros e atiradiços", "reinadio e mais patusco do que os ingleses", "malandro" (BRUN, 2015, p. 32). Bronco mas cordial, cortejador compulsivo de demoiselles, nostálgico do "bacalhau com batatas, sopa de grão, o belo casqueiro com a sua sardinha" (SAMPAIO, 1918, p. 201), escarnecido pelos boches pelo seu bizarro pelico alentejano, o soldado português parece, nestes textos, figura recortada de uma ópera bufa das trincheiras, herói inverosímil, mais propenso à farsa do que à epopeia ${ }^{14}$.

A inscrição ubíqua deste regime farsesco na literatura de guerra, já salientada por vários autores ${ }^{15}$, deverá entender-se como ponto de fuga compensatório e terapêutico, permitindo uma enunciação translata do horror pelo recurso a uma tática de atenuação tragicómica. "Quantas tragédias", reconhece André Brun, "degeneravam também em comédia!" 
(2014, p. 60). Frequentemente alinhado com uma intencionalidade satírica ou decetivamente (auto)irónica, o riso cúmplice ou disruptivo permite a sondagem contraépica das zonas de sombra que envolveram a intervenção portuguesa na guerra e que viriam a ser objeto de posterior escrutínio historiográfico: o incipiente treino militar dos soldados do Corpo Expedicionário Português (ironicamente designados como carneiros de exportação portuguesa), o brutal embate dos expedicionários com a terra incognita da Flandres, a convivialidade amistosa ou hostil entre os militares e as populações autóctones, a morte adiada nas trinchas, a carnificina burocratizada que permitiu acrescentar um canto burlesco à contraepopeia da Flandres:

Esta guerra ... é aquela a que melhor se adapta o feitio português. Como se sabe, o oficial lusitano foi sempre, nos tempos de paz, essencialmente funcionário, e não havia razões aparentes para que deixasse de sê-lo vindo para a guerra e se as circunstâncias o permitissem. Nesta guerra de trincheiras, de guarnições fixas e de sítios certos, está nas suas sete quintas. Montou muitas repartições, arranjou muitos empregos, criou muitos chefes - distinguem-se pela pala - rodeou-os de muitos adjuntos, deu-lhes muitos amanuenses e pôs-se a escrever, umas vezes à máquina, outras a lápis, o canto suplementar dos Lusíadas, que viemos compor a França, nos seguintes termos: - "Em referência à nota N. ${ }^{\circ} \mathrm{X}$ deste C., lembro a V. Ex ${ }^{\mathrm{a}}$ o disposto na alínea a) da O. S. $n^{\circ} 14381$ da R. E. do Q. G. do C.E.P, que altera o artigo $\mathrm{Y}$ da circular N. $\mathrm{Z}$ Z.- 0 . contendo as instruções a que se refere a determinação dos S. A. da 7. a B.I" (BRUN, 2014, p. 18).
Contrapeso derrisório para um trágico de outro modo improferível, o jocoso castrense que emerge como ingrediente narrativo imprescindível nestas crónicas de guerra cumpre, em primeira instância, uma óbvia função de comic relief. Mais importante, ao assinalar a intromissão do irrisório no teatro do quotidiano militar no front $^{16}$, ele mina os protocolos da dicção épica, opondo-lhe uma contra-dicção concretizada pelos modos do "mimético baixo" ou do "iróni-

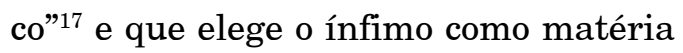
do canto, colocando em cena um herói sem qualidades. Se, em justificação preambular ao anedotário coligido em $O$ bom humor no C.E.P., esclarece o autor que se propôs "dizer alguma coisa sôbre o humor dos nossos soldados na Grande Guerra em França (1917-1918), para demonstrar que os Portugueses nem mesmo diante da morte, que os espreitava a cada momento, abandonavam a sua boa disposição de espírito" (CARVALHO, 1944, p. 16), a frequência de um auto- e hetero-humor de fundo antropológico e etnográfico ${ }^{18}$, assente na ridicularização pela estereotipia, parece sublinhar bastante mais a astuciosa engenhosidade do magala português do que a sua presteza bélica ${ }^{19}$. Sem tempo para nos demorarmos nos imagotipos, não raramente ambivalentes, construídos em torno de boches, tommies ou camones, porchises ou pork and beans ${ }^{20}$, e difundidos por estes textos, deixo registada a pertinência de um estudo que especificamente se dedique a averiguar o modo como, 
no memorialismo de guerra, o discurso de estereótipo assinala, para além de um tenso processo de negociação ditado pela natureza assimétrica das relações de poder que regulavam a sociabilidade de trincheira, a encenação estratégica de uma comédia de enganos transcultural, por meio da qual são agenciados processos binários de essencialização e de construção etnocêntrica da diferença, mas também de transferência e hibridismo:

Os camones escanhoados e fleumáticos, brunidos e engraxados, estendendo-se numa mancha cor de caqui desde Amiens até Dunkerque, não quadram nas primeiras impressões ao feitio do nosso João Ninguém. Sobretudo porque nestas regiões, tendo por seu lado o prestígio das libras, é sempre o seu competidor nos negócios de coração. Mas como são velhos aliados não têm outro remédio senão o de acomodar-se aos velhos hábitos guerreiros, começando por se treinar nos pickles e na compota de cascas de laranja.

De resto, João Ninguém gosta dos escoceses, homens das Terras Altas e de saias curtas, ao lado dos quais se bateu heroicamente no dia 9 de Abril, na defesa de Givenchy.

Também os canadianos, de chapéu de feltro levantado, são em geral comunicativos e simpáticos, mas os australianos, de chapéu à cowboy, sem porte militar e grosseiros, são sempre os antagonistas sovados nas rixas dos acampamentos.

No entanto, em todas as vicissitudes por que passou João Ninguém, ele deve reconhecer que o "camone", única palavra inglesa susceptível de entrar no seu ouvido, foi o companheiro leal que sempre lhe proporcionou inúmeras felicidades, abrindo-lhe as portas das cantinas e ordnances, onde os seus oficiais, mesmo os mais resistentes a se barbearem todos os dias, se "inglesaram" a pouco e pouco, adquirindo os bons impermeáveis, os sobretudos forrados de pele, os enormes "butes" de trincheira, luvas, cinturões, cigarros egípcios, guloseimas, etc., tudo enfim a que não estavam habituados muitos daqueles que só na guerra foram aprender certos hábitos de conforto e civilização, e que, com os novos uniformes, conseguiram espantar os seus superiores (FERREIRA, 2014, sem paginação).

Importaria examinar, neste contexto, o recurso assíduo ao expediente cómico do quiproquo, associado ao jargão das tropas ${ }^{21}$ ou ao uso que os soldados fazem da língua do pas compris:

Habilidosos e de genio inventivo os nossos serranos não se acanharam ao pisar as terras de França.

Tornam-se mesmo simpaticos e queridos dos habitantes, porque são muito mais reinadios do que os inglezes.

O seu bom humor não se altera nunca. Para eles não ha dificuldades; com palavras, com pantomimas adequadas fazem-se comprehender pelos francezes e até pelos inglezes, apezar de inventarem termos que nem existem na lingua dos antropófagos. Era a lingua do "pas compris" cosinhado de varios termos capaz de arripiar os cabelos a um esquimo (CARVALHO, 1944, p. 91).

Do mesmo modo, a cristalização aforística de hetero-imagens eufóricas dos soldados portugueses - les portugais sont toujours gais ou les portugais sont toujours chauds ${ }^{22}$ - parece sintoma de um panegírico deflacionário que, à falta de atributos verdadeiramente heroicos, prefere deslocar o louvor possível para a amenidade galanteadora dos "Franciscos, [d]os Manéis, [d]os Antónios, muito pândegos e piadistas, e um tanto lamechas que têm por aí aparecido em certas páginas" (CORTESÃO, 1969, p. 149) - atores de uma comédia de pilhérias e piropos, heróis sem aretê de um canto sem kléos. 


\section{Considerações finais}

Ao encerrar o volume das suas $M e$ mórias da Grande Guerra, lamentava-se Jaime Cortesão:

Tenho visto que os senhores se habituaram, pela leitura de certos relatos, a olhar o soldado da Grande Guerra como uma espécie de compadre de revista, com muita piada. [...] Os que o reduziram à caricatura grotesca de Zé Povinho reinadio das trincheiras, ou nunca o viram nesse lugar, ou lhe atribuem as suas próprias dimensões para não fazerem por sua vez triste figura. Assim, ficam todos pequenos (1969, p. 251).

Emissário, sem nome e sem rosto, da derrocada de um mundo épico, neste Zé Povinho das trincheiras pressente-se também uma reorientação da política da memória: numa guerra em que o anonimato garante o heroísmo de todos e de nenhum, já não há lugar para cantar a virtude do herói com rosto. Porque, com efeito, nela, "nenhum nome é preservado e nenhum homem recebe glória perene: o Soldado Desconhecido toma o lugar de Aquiles" (LEITÃO, 2010, p. 330).

\section{Zé Povinho in the trenches: epic and anecdote in Great War memoirs}

\section{Abstract}

In this article, based on a comparative reading of selected war memoirs by Portuguese combatants (such as Jaime Cortesão, Augusto Casimiro, Pina de Morais, Albino Forjaz de Sampaio e André Brun, among others), we seek to examine some of the key strategies of narrative reenactment of post-traumatic memory. We will particularly emphasize the stylistic effect achieved through the coexistence of an epic and celebratory tone with burlesque or elegiac miniloquence. This rhetorical ambivalence will be correlated with the essential mutation in the politics and the poetics of memory underlying these texts, according to which the epic hero of the past appears to have been replaced by the anonymous figure of the Unknown Soldier.

Keywords: War memoirs. Testimonial literature. Humor. Unknown Soldier.

\section{Notas}

1 Acrescenta ainda o autor: "But at the same time, soldier-writers brought the 'aesthetics of direct experience' to bear on imagining the war in a way far removed from the 'lies' or 'Big Words' of the older generation which sent them to fight and die in France and Flanders. [...] The second way of understanding the war entails what many modernists rejected: patriotic certainties, 'high diction' incorporating euphemisms about battle, 'glory', and the 'hallowed dead', in sum, the sentimentality and lies of wartime propaganda" (WINTER, 1995, p. 2).

2 Esclarece Denis Boak que "le souci du véridique, or what I myself term the 'mimetic imperative', explains the overwhelming choice of the memoir as a medium" (2012, p. 219).

3 "The war writers of 1914 did not, however, come to realism automatically: rhetorical notions of chivalrous patriotism, selfless gallantry, noble death in battle, the pious catchwords of jingoist literature which we now find so hard to swallow, were in the first place the accepted language of war. Dulce et decorum est pro patria mori, The Old Lie, as Wilfred Owen put it in one of his best-known poems. This had to be overcome before the factual mode of writing became the norm" (BOAK, 2012, p. 220).

4 Como, a esse respeito, salienta Paul Fussell, "the problem of the writer trying to describe 
elements of the Great War was its utterly incredibility, and thus its incommunicability in its own terms. As Bernard Bergonzi has said, "The literary records of the Great War can be seen as a series of attempts to evolve a response that would have some degree of adequacy to the unparalleled situation in which the writers were involved". Unprecedented meaning thus had to find precedent motifs and images" (2000, p. 139).

5 A propósito de Epopeia Maldita, de António de Cértima, observa justamente Ernesto Castro Leal: "O título escolhido para classificar o drama da guerra em África é já de si esclarecedor. Epopeia, logo narração heróica de uma gesta, mas, neste caso, a sua exemplaridade é maldita. Encontra-se já aqui uma primeira ideia-base: a dessacralização dos heróis. Estes são heróis actuais, em que o individual se plasma na sociedade do tempo, no entanto - e para isso apelará Cértima - possuem capacidade para forjar uma resposta à situação agónica de vivência" (1992, p. 515).

6 Como lembram Arthur Nestrovski e Márcio Seligmann-Silva, "o locus classicus do estudo moderno do trauma é o capítulo 18 das Conferências introdutórias de Freud. Ao estudar o caso de soldados austríacos retornando da Primeira Guerra atormentados por suas lembranças, mas incapazes de dizer uma palavra sobre o que viram, Freud define o trauma como 'uma experiência que traz à mente, num período curto de tempo, um aumento de estímulo grande demais para ser absorvido'. [...] A característica essencial do trauma é o adiamento, ou incompletude do que se sabe»". (2000, p. 8-9)

7 Inicialmente proposta por Hal Foster, a categoria do "realismo traumático" foi recuperada por Michael Rothberg a propósito da representação do Holocausto, que nela destaca a coexistência de "the minor and the catastrophic. This is indeed one place that traumatic realism draws on and deviates from the traditionally understood realist project". (2000, p. 135)

8 Salientando a natureza genologicamente fluida e o modesto escopo narrativo dos escritos de guerra produzidos em Portugal, concluía João Paulo Freire, em 1919, que "A guerra não deu em Portugal obra de fôlego. As crónicas de Adelino Mendes, Augusto de Castro, Hermano Neves, Forjaz de Sampaio, Almada Negreiros, Paulo Osório, André Brun, Xavier de Carvalho, José Pontes e Mário de Almeida, para não incluir as minhas, são tôdas meros episódios, pontos de vista jornalísticos, apreciações sôbre o joelho, mais ou menos bem lançadas com maior ou menor chama de sentimentalidade" (1919, p. 99-100).

9 Como oportunamente lembra Daniel Madelénat, "L'action épique - théodicée, ethnodicée ou anthropodicée - est une synthèse, et une herméneutique de l'histoire par le récit" (2009, p. 383).

10 Essa mesma homologia com a empresa expansionista, em conjunção com uma teoria do heroísmo de recorte carlyliano, rastreia-se também na obra de António de Cértima: "O recurso a essa espécie de 'idade de ouro' (epopeia dos Descobrimentos) conserva no presente um forte valor explicativo para Cértima. Aí se encontrava a tipificação do heroísmo de que a sociedade portuguesa necessitava". (LEAL, 1992, p. 516)

11 Omer Bartov acentua, nos seguintes termos, o declínio do paradigma de heroísmo bélicocavaleiresco precipitado pela Grande Guerra: "[...] the Great War, with its lethal combination of the machine gun and barbed wire, backed by heavy artillery capable of firing millions of shells [...] completely shattered the European image of war as an exercise in chivalry. [This] might have been expected to erase forever all romantic notions of battle, since that vast factory of death seemed to have destroyed the very elements of human individuality: courage, hope, enterprise, and a sense of the heroic possibilities in moral and physical conflict" (apud PRIOR, 2005, p. 44).

12 Como explica João Medina, "O Zé Povinho e o Camões mítico [...] surgem-nos assim como dois aspectos da nossa capacidade inovadora $\mathrm{e}$ geradora de mitos da geração setentista: trata-se de propor aos portugueses uma espécie de espelho nacional dos defeitos (Zé Povinho, o Labrego) e virtudes (Camões, o Bardo) dos próprios portugueses, da sua idiossincrasia, da sua 'alma', do seu dasein colectivo, da sua peculiar e irredutível maneira-de-ser, polos extremados do seu Imaginário: como Negativo, figura de caricatura realista [...] expressão do português tal qual, e, como Positivo, figura transfiguradora, idealizadora e capaz de suscitar, como paradigma de valores excelsos e inultrapassáveis (o Génio, a Literatura, a Epopeia nacional, a Pátria em Palavras, Portugal feito Verbo, etc.), o melhor que apresentavam um povo, uma colectividade e uma História, 
cujo passado se pretendia destarte recuperar, reassimilar e, retomando-o, nele configurar o presente de esqualidez e o futuro de Esperança. O Zé e sobretudo Camões-1880 são, pois, mitos, no sentido do poder de simbolização colectiva, de representação de estruturas imaginárias dum povo [...]". (1986, p. 11-12)

13 'Nem 'serrano', nem 'lanzudo', nem 'gambúzio', nem 'folgadinho'. Baptizá-lo-ei, muito simplesmente com o nome de João Ninguém, incarnando assim, nesta modesta alcunha, aquele português que nas horas difíceis tudo faz para maior glória da Pátria e a quem muitos esqueceram, chegada a hora dos benefícios e compensações" (FERREIRA, 2014, p. 64).

14 Como observa Paul Fussell, "if 'real life' is 'real', then military life must be pretense. The wearing of 'costumes' not chosen by their wearers augments the sense of the theatrical. So does the availability of a number of generically rigid stage character-types, almost like those of Comedy of Humors: the helpless Private, the vainglorious Corporal, the sadistic Sergeant, the adolescent, snobbish Lieutenant, the fireeating Major, the dotty Colonel" (2000, p. 191).

15 Samuel Hynes argumenta, por exemplo, que "irony is the inescapable tone of modern war". (apud GRIET, 2009, p. 169). Dessa vocação expressamente humorística se reclamam, por exemplo, as obras intituladas $O$ bom humor no C.E.P. França 1917-1981, do Major Mário Affonso de Carvalho, ou João Ninguém, Soldado da Grande Guerra, do capitão Menezes Ferreira.

16 "The whole thing is too grossly farcical, perverse, cruel, and absurd to be credited as a form of 'real life'. Seeing warfare as theater provides a psychic escape for the participant: with a sufficient sense of theater, he can perform his duties without implicating his 'real' self and without impairing his innermost conviction that the world is still a rational place" (FUSSELL, 2000, p. 192).

17 A distinção proposta por Northrope Frye entre os modos que designa por "high mimetic", "low mimetic" e "ironic" é transposta por Paul Fussell para o memorialismo da Grande Guerra nos seguintes termos: "As he continues to set forth his 'Theory of Modes', Frye indicates that the modes in which the hero's power of action is greater than ours are myth, romance, and the 'high mimetic' of epic and tragedy; the mode in which the hero's power of action is like ours is the 'low mimetic', say, of the eighteenth- and nineteenth-century novel; and the mode in which the hero's power of action is less than ours is the 'ironic', where 'we have the sense of looking down on a scene of bondage, frustration, or absurdity.... [...] The passage of these literary characters from prewar freedom to wartime bondage, frustration, and absurdity signals [...] the passage of modern writing from one mode to another, from the low mimetic of the plausible and the social to the ironic of the outrageous, the ridiculous, and the murderous. It is their residence on the knife-edge between these two modes that gives the memoirs of the Great War their special quality [...]. These memoirs are especially worthy of the closest examination because, for all the blunt violence they depict, they seem so delicately transitional, pointing at once in two opposite directions - back to the low mimetic, forward to the ironic and - most interestingly - to that richest kind of irony proposing, or at least recognizing, a renewed body of rituals and myths" (2000, p. 311-12).

18 Como nota Ernesto Castro Leal, "sendo uma constante nas narrativas guerristas a evocação do heroísmo dos soldados, tal não obstou a que se produzisse uma leitura antropológica dos seus hábitos profundos [...]" (2000, p. 448).

19 Como refere o major Mário Afonso de Carvalho, "sobre o bom humor na vida diaria da campanha, muito ha que contar e ele revelou-se tambem d'uma forma notavel, quer nas proprias linhas de combate, quer no convivio com os habitantes em que devido ao desconhecimento da lingua franceza por parte da quasi totalidade dos combatentes portuguezes teve aspectos d'um cómico irresistível". (1944, p. 46)

20 "A má apresentação visual do militar português criava uma imagem negativa. A inadaptação ao clima da Flandres e às características da guerra de trincheiras do vestuário e do calçado utilizados pelo militar português, obrigando-o a recorrer a peças não convencionadas e em desacordo com o uniforme de campanha, e o comprimento do seu cabelo impressionavam negativamente dado o consequente 'aspeto ascuroso', motivador da atribuição britânica do epíteto 'porchises' aos militares portugueses, altamente depreciativo. [...] Ironia, também, presente na atribuição inglesa de mais uma alcunha ao militar português devido à estranheza dos gostos gastronómicos portugueses: a preferência portuguesa pelo feijão com carne de porco ao insípido corned beef, chá e frutas cristalizadas da ração britânica originou a alcunha 
'pork and beans', imediatamente considerada ofensiva e motivo de zaragata" (MARQUES, 2008, p. 340-341).

21 "Para o Joaquim fugir é cavar; as trincheiras são as trinchas; a metralhadora é uma costureira; os oficiais que não estão com êle nas trinchas são cachapins. Cachapins ligeiros os do batalhão, médios os da brigada, pesados os da divisão. Um oficial de sapadores é um dos trabalhos encravados; 'corn beef' é o fiel amigo; o 'jambom' é o 365 de campanha; um oficial provisor é o vintém de trigo" (SAMPAIO, 1918, p. 196).

22 "O amor é belo!... É um fraco dos portuguezes o seu feitio conquistador. Foram sempre femieiros, muito atiradiços mesmo e este defeito já vem do tempo de D. Afonso Henriques. Não admira pois, que ao pisarem terras de França, se metessem logo á conquista dos corações das gentis e elegantes francezinhas, que perante suas arremetidas diziam graciosamente: 'Oh! les portugais sont très chauds!...'” (SAMPAIO, 1918, p. 88-89).

\section{Referências}

BENJAMIN, Walter. Experiência e Pobreza. In ___ O anjo da história. Belo Horizonte: Autêntica Editora, 2012, p. 85-90.

BOAK, Denis. The Mimetic Imperative: War, Fiction, Realism». Romance Studies, Swansea, v. 30, n. 3-4, p. 217-228, jul. 2012.

BRUN, André. A malta das trincheiras. Migalhas da Grande Guerra: 1917-1918. Lisboa: Guerra e Paz Editores, 2014.

CARVALHO, Major Mario Affonso de. O bom humor no C.E.P. (França 1917-1918). Lisboa: Serviços Gráficos do Exército, 1944.

CASIMIRO, Capitão Augusto. Nas Trincheiras da Flandres. Porto: Edição da Renascença Portuguesa, 1917.

CORTESÃO, Jaime. Memórias da Grande Guerra. Lisboa: Portugália Editora, 1969.

FERREIRA, Capitão Menezes. João Ninguém. Soldado da Grande Guerra. Lisboa: Bertrand Editora, 2014.
FREIRE, João Paulo. Albino Forjaz de Sampaio (escôrço bio-bibliográfico). Porto: Editores Santos \& Vieira, 1919.

FUSSELL, Paul. The Great War and Modern Memory. Oxford: Oxford University Press, 2000.

LEAL, Ernesto Castro. Heroísmo em António de Cértima: psicologia e sociedade. In: SERRÃO, Joaquim Veríssimo (Org.). Estudos de Homenagem a Jorge Borges de Macedo. Lisboa: INIC, 1992, p. 505-523.

Narrativas e imaginários da $1^{-}$Grande Guerra. O 'Soldado-Saudade' português nos 'nevoeiros da morte'. Revista de História das Ideias, Coimbra, vol. 21, p. 441-460, 2000.

MADELÉNAT, Daniel. Présence paradoxale de l'épopée: hors d'âge et sur le retour. In: NEIVA, Saulo (Org.). Désirs et débris d'épopée au XXe siècle. Bern: Peter Lang, 2009, p. 379-391.

MARQUES, Isabel Pestana. Das trincheiras com saudade. A vida quotidiana dos militares portugueses na Primeira Guerra Mundial. Lisboa: A Esfera dos Livros, 2008.

MEDINA, João. Zé Povinho e Camões: dois polos da prototipia nacional. Colóquio/Letras, Lisboa, n. 92, p. 11-21, jul. 1986.

MORAIS, Tenente Pina de. Ao Parapeito. Porto: Edição da Renascença Portuguesa, 1919.

NEGREIROS, José de Almada. Ultimatum futurista às gerações portuguesas do Século XX. In: Portugal Futurista. Edição fac-similada. Lisboa: Contexto, 1984, p. 36-38.

NEIVA, Saulo. Présentation. In: (Org.). Désirs et débris d'épopée au XX̄e siècle. Bern: Peter Lang, 2009, p. ix-xii.

NESTROVSKI, Arthur; SELIGMANN-SILVA, Márcio. Apresentação. In:

(Orgs.). Catástrofe e Representação. São Paulo: Escuta, 2000, p. 7-12. 
PRIOR, Robin. The Heroic Image of the Warrior in the First World War. War \& Society, The University of New South Wales, v. 23, p. 43-51, set. 2005.

RICGUR, Paul. La mémoire, l'histoire, l'oubli. Paris: Seuil, 2000.

ROTHBERG, Michael. Traumatic Realism. The Demands of Holocaust Representation. Minneapolis: University of Minnesota Press, 2000 .

SAMPAIO, Albino Forjaz de. A Avalanche (À Margem da Grande Guerra). Lisboa: Editores Santos \& Vieira-Empresa Literária Fluminense, 1918.

SELIGMANN-SILVA, Márcio. O Local do Testemunho. Tempo e Argumento, Florianópolis, v. 2, n. 1, p. 3-20, jan./jun. 2010.

THEETEN, Griet. La Grande Guerre en fiction. La représentation de la Première Guerre mondiale dans la littérature française de l'extrême contemporain. Gent: Universiteit Gent. 2009.

VIEIRA, Luiz Gustavo Leitão. O anonimato do herói: Aquiles e o Soldado Desconhecido na narrativa de guerra. In: CORNELSEN, Elcio; BURNS, Tom (Org.). Literatura e Guerra. Belo Horizonte: Editora UFMG, 2010, p. 305-330.

WINTER, Jay. Sites of Memory, Sites of Mourning. The Great War in European Cultural History. Cambridge: Cambridge University Press, 1995. 